\title{
Reduksi Tingkat Kebisingan Kendaraan Bermotor Dengan Penghalang Alami Berupa Panjang Klaster Tanaman
}

\author{
Jumingin $^{1 *}$, Atina ${ }^{2}$ \\ *e-mail: juminginpgri@gmail.com \\ ${ }^{1}$ Program Studi Fisika, Fakultas MIPA, Universitas PGRI Palembang 30251, Indonesia \\ ${ }^{2}$ Program Studi Fisika, Fakultas MIPA, Universitas PGRI Palembang 30251, Indonesia
}

\begin{abstract}
Research on motor vehicle noise reduction has been carried out with natural barriers in the form of plant cluster lengths. The purpose of this study was to determine the effect of plant cluster length as a natural barrier to reduce motor vehicle noise levels. This study uses a purposive sampling method, where in the study of noise level measurements carried out at selected points and determined in accordance with existing plant clusters at the study site. The tools used in this study are sound level meter, stopwatch, roll meter and tripod. Sound level meters are placed in front of plant clusters and behind plant clusters at a height of $120 \mathrm{~cm}$ above ground level. The noise level in front of and behind the planting cluster is measured simultaneously for 30 days during the daytime measurement activity. The data obtained were analyzed using one factorial variance analysis in the form of plant cluster length. The results showed that the noise reduction by the cluster of cape, bungur, Tembesi, mahogany and palm clusters with a cluster length of $25 \mathrm{~m}$ was $10.5 \mathrm{~dB} ; 8,6 \mathrm{~dB} ; 9,1 \mathrm{~dB} ; 5,4 \mathrm{~dB}$ and $5,2 \mathrm{~dB}$, the length of the $20 \mathrm{~m}$ plant cluster is $9.5 \mathrm{~dB} ; 7.5 \mathrm{~dB} ; 6,4 \mathrm{~dB} ; 4.0 \mathrm{~dB}$ and $4.4 \mathrm{~dB}$, the plant cluster length of $17.5 \mathrm{~m}$ is $5.9 \mathrm{~dB} ; 5,8 \mathrm{~dB} ; 5,1 \mathrm{~dB} ; 3,4 \mathrm{~dB}$ and $3,8 \mathrm{~dB}$, the length of the $15 \mathrm{~m}$ plant cluster is $4.2 \mathrm{~dB} ; 3,5 \mathrm{~dB} ; 3,9 \mathrm{~dB} ; 2,9 \mathrm{~dB}$ and $3,1 \mathrm{~dB}$, the length of the $10 \mathrm{~m}$ plant cluster is $3,8 \mathrm{~dB} ; 3,3 \mathrm{~dB} ; 2,7 \mathrm{~dB} ; 2,3 \mathrm{~dB}$ and $2,7 \mathrm{~dB}$, and the $7.5 \mathrm{~m}$ plant cluster length is $3,08 \mathrm{~dB} ; 3,1 \mathrm{~dB} ; 1,6 \mathrm{~dB} ; 1.7 \mathrm{~dB}$ and $1.8 \mathrm{~dB}$. From BNT test with $99 \%$ confidence level showed that the greater difference in plant cluster length has a very significant effect on noise level reduction.
\end{abstract}

Keywords: Natural barrier, plant cluster length, noise level reduction

\begin{abstract}
ABSTRAK
Telah dilakukan penelitian tentang reduksi kebisingan kendaraan bermotor dengan penghalang alami berupa panjang klaster tanaman. Tujuan dari penelitian ini adalah untuk mengetahui pengaruh panjang klaster tanaman sebagai penghalang alami untuk mereduksi tingkat kebisingan kendaraan bermotor. Penelitian ini menggunakan metode Purpossive sampling, dimana dalam penelitian pengukuran tingkat kebisingan dilakukan pada titik-titik yang dipilih dan ditentukan sesuai dengan klaster tanaman yang ada di lokasi penelitian. Alat yang digunakan dalam penelitian ini adalah sound level meter, stopwatch, roll meter dan tripod. Sound level meter diletakkan di depan klaster tanaman dan di belakang klaster tanaman pada ketinggian $120 \mathrm{~cm}$ di atas permukaan tanah. Tingkat kebisingan di depan dan di belakang klaster tanamnan diukur secara bersamaan selama 30 hari pada waktu aktivitas pengukuran siang hari. Data yang diperoleh dianalisis menggunakan analisis sidik ragam satu faktorial berupa panjang klaster tanaman. Hasil penelitian menunjukan bahwa reduksi kebisingan oleh klaster tanaman bunga tanjung, bungur, tembesi, mahoni dan palem dengan panjang klaster tanaman $25 \mathrm{~m}$ adalah $10,5 \mathrm{~dB} ; 8,6 \mathrm{~dB} ; 9,1 \mathrm{~dB} ; 5,4 \mathrm{~dB}$ dan $5,2 \mathrm{~dB}$, panjang klaster
\end{abstract}


tanaman $20 \mathrm{~m}$ adalah $9,5 \mathrm{~dB} ; 7,5 \mathrm{~dB} ; 6,4 \mathrm{~dB} ; 4,0 \mathrm{~dB}$ dan $4,4 \mathrm{~dB}$, panjang klaster tanaman $17,5 \mathrm{~m}$ adalah $5,9 \mathrm{~dB} ; 5,8 \mathrm{~dB} ; 5,1 \mathrm{~dB} ; 3,4 \mathrm{~dB}$ dan $3,8 \mathrm{~dB}$, panjang klaster tanaman $15 \mathrm{~m}$ adalah $4,2 \mathrm{~dB} ; 3,5 \mathrm{~dB} ; 3,9 \mathrm{~dB} ; 2,9 \mathrm{~dB}$ dan $3,1 \mathrm{~dB}$, panjang klaster tanaman $10 \mathrm{~m}$ adalah $3,8 \mathrm{~dB} ; 3,3 \mathrm{~dB} ; 2,7 \mathrm{~dB} ; 2,3 \mathrm{~dB}$ dan $2,7 \mathrm{~dB}$, dan panjang klaster tanaman $7,5 \mathrm{~m}$ adalah $3,08 \mathrm{~dB} ; 3,1 \mathrm{~dB} ; 1,6 \mathrm{~dB} ; 1,7 \mathrm{~dB}$ dan 1,8dB. Dari uji BNT dengan tingkat kepercayaan 99\% menunjukan bahwa semakin besar perbedaan panjang klaster tanaman berpengaruh yang sangat nyata terhadap reduksi tingkat kebisingan.

Kata Kunci: Penghalang alami, panjang klaster tanaman, reduksi tingkat kebisingan.

\section{PENDAHULUAN}

Infrastruktur di Kota Palembang beberapa tahun terakhir terus dilakukan pembangunan dan perbaikan, khususnya jalan raya baik berupa jalan dalam kota maupun jalan provinsi. Pembangunan jalan raya tersebut diharapkan dapat meningkatkan kenyamanan pengguna jalan terutama dalam mengurai kemacetan dan memperindah lingkungan perkotaan. Pembangunan infrastruktur terutama jalan raya didasari oleh adanya peningkatan jumlah kendaraan di Kota Palembang, baik kendaraan roda dua maupun kendaraan roda empat. Menurut badan pusat statistik Provinsi Sumatera Selatan (2019), jumlah kendaraan di kota Palembang pada tahun 2015 sebanyak 572381 kendaraan, tahun 2016 sebanyak 667786 kendaraan dan tahun 2017 sebanyak 514245 kendaraan.

Semakin tingginya jumlah kendaraan di Kota Palembang semakin besar volume jalan yang diperlukan untuk menampung kendaraan-kendaraan tersebut. Beberapa wilayah di Kota Palembang terus ditingkatkan infrastrukturnya, salah satunya wilayah Kecamatan Alang-Alang Lebar. Di Kecamatan ini terdapat jalan By Pass Alang-Alang Lebar yang menghubungkan jalan Soekarno-Hatta dengan jalan Palembang-Jambi. Jalan ini dilalui oleh kendaraan bermotor baik roda dua maupun roda empat (baik kendaraan ringan maupun kendaraan berat) semakin ramai setelah selesainya pembangunan flyover di simpang bandara Sultan Mahmud Baddarudin II.
Peningkatan jumlah kendaraan bermotor tentunya akan memiliki dampak terhadap lingkungan terutama polusi suara atau kebisingan. Menurut Putri et al (2016), meningkatnya jumlah kendaaran yang melintas menyebabkan meningkatnya tingkat kebisingan di ruasruas jalan yang ada di Kota Pekanbaru. Disamping jumlah kendaraan, volume kendaraan juga berpengaruh terhadap tingkat kebisingan yang ditimbulkan. Hasil penelitian Rahmatunnisa et al (2017), bahwa semakin besar volume kendaraan maka semakin rendah kecepatan kendaraan sehingga menghasilkan tingkat kebisingan yang tinggi dan sebaliknya.

Pengendalian

kebisingan kendaraan bermotor di jalan raya dapat dilakukan dengan cara memasang penghalang antara sumber bunyi dengan penerima. Penghalang tersebut dapat berupa penghalang buatan atau penghalang alami. Menurut Kusminingrum (2008), salah satau upaya untuk mengurangi kebisingan yaitu dengan membuat penghalang bising misalnya penggunaan tanaman sebagai penghalang alami. Untuk mengendalikan kebisingan pada media perambatan dapat dilakukan dengan dua cara, yaitu kontrol rambatan outdoor dan kontrol rambatan indoor. Pengendalian rambatan outdoor misalnya pengurangan suara oleh serapan udara, pengurangan oleh vegetasi dan pengurangan oleh penghalang (Heryanto, 2004).

Gelombang bunyi akan mengalami pemantulan, pembiasan, 
hamburan dan penyerapan jika mengenai penghalang. Batang pohon merupakan aktor utama yang dapat memantulkan kebisingan jalan raya, sehingga tidak seluruh sumber bunyi sampai ke pendengar (Nilson et al, 2015). Menurut Samara dan Tsitsoni (2007), bahwa penurunan kebisingan setelah melewati pohon pelindung lebih signifikan dibandingkan dengan penurunan kebisingan di atas permukaan tanah yang tertutup rerumputan.

Penelitian ini bertujuan untuk mengetahui pengaruh panjang klaster tanaman sebagai penghalang alami untuk mereduksi tingkat kebisingan kendaraan bermotor. Manfaat penelitian ini diharapkan memberikan informasi hubungan panjang klaster tanaman yang digunakan sebagai penghalang alami untuk mereduksi kebisingan.

\section{BAHAN DAN METODE}

Penelitian ini merupakan pengukuran langsung data yang ada di lapangan berupa tingkat kebisingan kendaraan bermotor di depan dan di belakang klaster tanaman. Penelitian ini dilaksanakan selama 30 hari pada waktu aktivitas siang hari dari tanggal $2-31$ Mei 2019 di Jalan By Pass Alang-Alang Lebar Kota Palembang. Alat yang digunakan dalam penelitian ini adalah sound level meter, stopwatch, roll meter dan tripod.

Metode yang digunakan dalam penelitian ini adalah purpossive sampling, pengukuran yang dilakukan sesuai dengan klaster dan panjang klaster tanaman yang dijumpai di lokasi penelitian. Pada kegiatan penelitian ini terbagi dalam dua kegiatan penelitian, yaitu survey pendahuluan (dilakukan pengamatan dan pengukuran panjang kalster tanaman), dan pengukuran tingkat kebisingan di depan dan di belakang klaster tanaman. Pengukuran tingkat kebisingan di depan dan di belakang klaster tanaman dilakukan pada aktivitas pengukuran siang hari pada pukul: 07.00WIB (mewakili pukul 06.00 09.00WIB), 10.00WIB (mewakili pukul 09.00 - 11.00WIB), 15.00WIB (mewakili pukul $11.00-17.00 \mathrm{WIB}$ ), dan 20.00WIB (mewakili pukul 17.00 - 22.00WIB). Pengukuran tingkat kebisingan di depan dan di belakang klaster tanaman dilakukan serentak dan dibaca setiap 5 detik selama 10 menit pada masingmasing waktu pengukuran (KepMen LH, 1996). Sound level meter diletakan pada ketinggian $120 \mathrm{~cm}$ di atas permukaan tanah (Fang \& Ling, 2003).

Data yang telah diolah dianalisis menggunakan analisis sidik ragam satu faktorial dengan faktorial berupa panjang klaster tanaman dengan tingkat kepercayaan 95\%. Jika hasil analisis sidik ragam panjang klaster tanaman berpengaruh nyata terhadap reduksi tingkat kebisingan, maka dilakukan uji lanjut dengan uji beda nyata terkecil $(\alpha=1 \%)$.

\section{HASIL DAN PEMBAHASAN}

Dari penelitian yang dilakukan, pada kegiatan survey pendahuluan di Jalan By Pass Alang-Alang Lebar Kota Palembang ditemukan lima klaster tanaman yaitu klaster tanaman bunga tanjung, klaster tanaman bungur, klaster tanaman tembesi, klaster tanaman mahoni dan klaster tanaman palem. Dengan panjang kalster tanaman yang ditemui dengan ukuran $25 \mathrm{~m}, 20 \mathrm{~m}, 17,5 \mathrm{~m}, 15 \mathrm{~m}$, $10 \mathrm{~m}$, dan $7,5 \mathrm{~m}$.

Hasil pengukuran tingkat kebisingan di Jalan By Pass Alang-Alang Lebar Kota Palembang selama aktivitas siang hari selama 30 hari disajikan dalam Tabel 1 berikut: 
Tabel 1. Hasil pengukuran tingkat kebisingan di Jalan By Pass Alang-Alang Lebar Kota Palembang selama aktivitas siang hari selama 30 hari

\begin{tabular}{|c|c|c|c|c|}
\hline \multirow[t]{2}{*}{$\begin{array}{l}\text { Panjang } \\
\text { Klaster } \\
\text { (m) }\end{array}$} & \multicolumn{2}{|c|}{$\begin{array}{c}\text { Tingkat } \\
\text { Kebisingan } \\
(\mathrm{dB})\end{array}$} & \multirow{2}{*}{$\begin{array}{c}\text { Reduksi } \\
\text { Tingkat } \\
\text { Kebisingan } \\
\text { (dB) }\end{array}$} & \multirow[t]{2}{*}{ Ket } \\
\hline & $\mathrm{TS}_{1}$ & $\mathrm{TS}_{2}$ & & \\
\hline \multirow{5}{*}{25} & 70,9 & 60,4 & 10,5 & A \\
\hline & 70,3 & 61,7 & 8,6 & B \\
\hline & 71,0 & 61,9 & 9,1 & $\mathrm{C}$ \\
\hline & 71,6 & 66,2 & 5,4 & $\mathrm{D}$ \\
\hline & 71,9 & 66,7 & 5,2 & $E$ \\
\hline \multirow{5}{*}{20} & 70,8 & 61,3 & 9,5 & A \\
\hline & 71,8 & 64,3 & 7,5 & B \\
\hline & 70,8 & 64,4 & 6,4 & $\mathrm{C}$ \\
\hline & 69,2 & 65,2 & 4,0 & $\mathrm{D}$ \\
\hline & 71,8 & 67,4 & 4,4 & $\mathrm{E}$ \\
\hline \multirow{5}{*}{17,5} & 70,9 & 65,0 & 5,9 & A \\
\hline & 70,9 & 65,1 & 5,8 & B \\
\hline & 71,5 & 66,4 & 5,1 & $\mathrm{C}$ \\
\hline & 70,3 & 66,9 & 3,4 & D \\
\hline & 70,7 & 66,9 & 3,8 & $E$ \\
\hline \multirow{5}{*}{15} & 70,6 & 66,4 & 4,2 & $\mathrm{~A}$ \\
\hline & 69,4 & 65,9 & 3,5 & B \\
\hline & 72,1 & 68,2 & 3,9 & $\mathrm{C}$ \\
\hline & 69,7 & 66,8 & 2,9 & $\mathrm{D}$ \\
\hline & 70,5 & 67,4 & 3,1 & $E$ \\
\hline \multirow{5}{*}{10} & 70,7 & 66,9 & 3,8 & $\mathrm{~A}$ \\
\hline & 70,2 & 66,9 & 3,3 & $\mathrm{~B}$ \\
\hline & 69,7 & 67,0 & 2,7 & C \\
\hline & 68,8 & 66,5 & 2,3 & $\mathrm{D}$ \\
\hline & 69,9 & 67,2 & 2,7 & $\mathrm{E}$ \\
\hline \multirow{5}{*}{7,5} & 70,6 & 67,6 & 3,0 & $\mathrm{~A}$ \\
\hline & 71,5 & 68,4 & 3,1 & $\mathrm{~B}$ \\
\hline & 69,2 & 67,6 & 1,6 & $\mathrm{C}$ \\
\hline & 67,9 & 66,2 & 1,7 & $\mathrm{D}$ \\
\hline & 70,1 & 68,3 & 1,8 & $E$ \\
\hline
\end{tabular}

Keterangan:

A: Klaster Tanaman Bunga Tanjung

B: Klaster Tanaman Bungur

C: Klaster Tanaman Tembesi

D: Klaster Tanaman Mahoni

E: Klaster Tanaman Palem

Dari Tabel 1 di atas terlihat bahwa semakin panjang klaster tanaman tingkat reduksi kebisingan yang dihasilkan semakin besar. Panjang klaster tanaman yang semakin besar menyebabkan semakin kecil suara yang sampai pada penerima suara yang berada di belakang klaster tanaman. Panjang klaster tanaman yang semakin panjang akan dapat menyerupai bangunan tembok, sehingga bunyi yang datang ke sound level meter terhalang oleh keberadaan kalster tanaman tersebut. Menurut Umiati (2012), bahwa penggunaan pagar pembatas dapat mengurangi kebisingan.

Dari Tabel 1 juga terlihat bahwa untuk klaster tanaman bunga tanjung memiliki kemampuan untuk mereduksi kebisingan yang paling tinggi, karena klaster bunga dianjung ditanam dengan kerapatan yng lebih tinggi dibandingkan klaster tanaman bungur, mahoni, dan tembesi. Bunga tanjung memiliki kerapatan daun yang rapat, berukuran kecil, cabang dan ranting pohon yang banyak, sehingga kebisingan yang diterima oleh sound level meter di belakang pohon menjadi lebih rendah. Hal ini terjadi karena adanya peristiwa pemantulan, pembiasan, hamburan dan penyerapan (absorpsi) bunyi oleh daun, cabang dan ranting tanaman. Tanaman yang memiliki jumlah daun yang banyak lebih mampu mengurangi kebisingan dibandingkan dengan tanaman dengan jumlah daun yang sedikit (Price, 1988).

Dari tabel 1 juga terlihat bahwa untuk panjang klaster tanaman $7,5 \mathrm{~m}$, $10 \mathrm{~m}, 15 \mathrm{~m}, 17,5 \mathrm{~m}$ dan $20 \mathrm{~m}$ reduksi kebisingan oleh klaster tanaman palem lebih tinggi dibandingkan oleh klaster tanaman mahoni. Hal ini terjadi karena kerapatan tanaman palem lebih rapat dibandingkan dengan kerapatan tanaman mahoni pada jarak tersebut. Untuk panjang klaster $15 \mathrm{~m}$ dan $25 \mathrm{~m}$, kerapatan tanaman tembesi lebih rapat dibandingkan dengan klaster tanaman bungur. Untuk panjang kalster $7,5 \mathrm{~m}$, klaster tanaman mahoni memiliki kerapatan yang lebih rapat klaster tanaman tembesi. Pola penanaman tanaman dengan kerapatan yang tinggi sehingga menyerupai tembok atau 
penghalang bangunan dapat mengurangi kebisingan (Hidayat, 2010).

Analisis sidik ragam antara panjang klaster tanaman dengan reduksi tingkat kebisingan kendaraan bermotor disajikan dalam Tabel 2 berikut:

Tabel 2. Analisis Sidik Ragam Panjang Klaster Tanaman dengan Reduksi Tingkat Kebisingan dengan tararf signifikansi $(\alpha=5 \%)$.

\begin{tabular}{|c|c|c|c|c|c|c|}
\hline \multirow{2}{*}{ Panjang Klaster Tanaman } & \multicolumn{7}{|c|}{ Taraf Signifikansi $(\alpha=5 \%)$} \\
\cline { 2 - 7 } & $25 \mathrm{~m}$ & $20 \mathrm{~m}$ & $17,5 \mathrm{~m}$ & $15 \mathrm{~m}$ & $10 \mathrm{~m}$ & $7,5 \mathrm{~m}$ \\
\hline $25 \mathrm{~m}$ & - & 0,148 & $0,004^{*}$ & $0,000^{*}$ & $0,000^{*}$ & $0,000^{*}$ \\
\hline $20 \mathrm{~m}$ & 0,148 & - & 0,109 & $0,006^{*}$ & $0,001^{*}$ & $0,000^{*}$ \\
\hline $17,5 \mathrm{~m}$ & $0,004^{*}$ & 0,109 & - & 0,185 & 0,061 & $0,012^{*}$ \\
\hline $15 \mathrm{~m}$ & $0,000^{*}$ & $0,006^{*}$ & 0,185 & - & 0,556 & 0,185 \\
\hline $10 \mathrm{~m}$ & $0,000^{*}$ & $0,001^{*}$ & 0,061 & 0,556 & - & 0,450 \\
\hline $7,5 \mathrm{~m}$ & $0,000^{*}$ & $0,000^{*}$ & $0,012^{*}$ & 0,185 & 0,450 & - \\
\hline
\end{tabular}

Ket. * adanya perbedaan nyata

Dari tabel 2 di atas terlihat bahwa perbedaan panjang klaster tanaman yang cukup besar menunjukan adanya perbedaan yang nyata dalam menghasilkan reduksi kebisingan. Tetapi untuk perbedaan panjang klaster tanaman yang kecil, menunjukan adanya perbedaan yang tidak nyata dalam mereduksi kebisingan. Untuk panjang klaster tanaman $25 \mathrm{~m}$ dan $17,5 \mathrm{~m}$ (berbeda sebesar 7,5m), $25 \mathrm{~m}$ dan $15 \mathrm{~m}$ (berbeda $10 \mathrm{~m}$ ), $25 \mathrm{~m}$ dan $10 \mathrm{~m}$ (berbeda $15 \mathrm{~m}$ ), serta $25 \mathrm{~m}$ dan $7,5 \mathrm{~m}$ (berbeda 17,5m) menunjukan adanya perbedaan yang nyata dalam mereduksi kebisingan. Sedangkan panjang klaster tanaman $25 \mathrm{~m}$ dan 20m (berbeda sebesar 2,5m) menunjukan adanya perbedaan yang tidak nyata dalam mereduksi kebisingan.

Untuk panjang klaster tanaman $20 \mathrm{~m}$ dan $15 \mathrm{~m}$ (berbeda sebesar $5 \mathrm{~m}$ ), $20 \mathrm{~m}$ dan $10 \mathrm{~m}$ (berbeda $10 \mathrm{~m}$ ), $20 \mathrm{~m}$ dan $7,5 \mathrm{~m}$ (berbeda 12,5m), menunjukan adanya perbedaan yang nyata dalam mereduksi kebisingan. Sedangkan panjang klaster tanaman $20 \mathrm{~m}$ dan $17,5 \mathrm{~m}$ (berbeda sebesar 2,5m) menunjukan adanya perbedaan yang tidak nyata dalam mereduksi kebisingan. Untuk panjang klaster tanaman $17,5 \mathrm{~m}$ dan $15 \mathrm{~m}$ (berbeda sebesar 2,5m), 17,5m dan $15 \mathrm{~m}$ (berbeda $5 \mathrm{~m})$ menunjukan adanya perbedaan yang tidak nyata dalam mereduksi kebisingan. Sedangkan panjang klaster tanaman 17,5m dan 7,5m (berbeda sebesar 10m) menunjukan adanya perbedaan yang nyata dalam mereduksi kebisingan.

Kemudian dilakukan uji lanjut dengan menggunakan uji beda nyata terkecil antara panjang klaster tanaman dengan reduksi tingkat kebisingan untuk mengetahui panjang klaster tanaman yang memberikan perbedaan yang sangat nyata dalam mereduksi kebisingan. Hasil uji beda nyata terkecil antara panjang klaste tanaman untuk mereduksi kebisingan disajikan dalam Tabel 3 berikut: 
Tabel 3. Uji beda nyata terkecil panjang klaster tanaman dalam mereduksi tingkat kebisingan

\begin{tabular}{|c|c|c|c|c|c|c|}
\hline \multirow{2}{*}{ Panjang Klaster Tanaman } & \multicolumn{7}{|c|}{ Taraf Signifikansi $(\alpha=1 \%)$} \\
\cline { 2 - 7 } & $25 \mathrm{~m}$ & $20 \mathrm{~m}$ & $17,5 \mathrm{~m}$ & $15 \mathrm{~m}$ & $10 \mathrm{~m}$ & $7,5 \mathrm{~m}$ \\
\hline $25 \mathrm{~m}$ & - & 1 & 0,064 & $0,002^{*}$ & $0,000^{*}$ & $0,000^{*}$ \\
\hline $20 \mathrm{~m}$ & 1 & - & 1 & 0,087 & 0,02 & $0,003^{*}$ \\
\hline $17,5 \mathrm{~m}$ & 0,064 & 1 & - & 1 & 0,921 & 0,175 \\
\hline $15 \mathrm{~m}$ & $0,002^{*}$ & 0,087 & 1 & - & 1 & 1 \\
\hline $10 \mathrm{~m}$ & $0,000^{*}$ & 0,02 & 0,921 & 1 & - & 1 \\
\hline $7,5 \mathrm{~m}$ & $0,000^{*}$ & $0,003^{*}$ & 0,175 & 1 & 1 & - \\
\hline
\end{tabular}

Ket. * adanya perbedaan yang sangat nyata

Dari Tabel 3 diatas terlihat bahwa adanya perbedaan yang sangat nyata dari panjang klaster tanaman untuk mereduksi tingkat kebisingan. Dari Tabel tersebut terlihat bahwa reduksi tingkat kebisingan oleh klaster tanaman berbeda sangat nyata jika perbedaan panjang klaster tanaman semakin besar. Perbedaan reduksi tingkat kebisingan oleh panjang klaster tanaman $25 \mathrm{~m}$ dan $15 \mathrm{~m}$ (selisih $10 \mathrm{~m})$ berbeda sangat nyata dengan signifikansi kurang dari 1\% (yaitu 0,2\%). Perbedaan reduksi tingkat kebisingan oleh panjang klaster tanaman $25 \mathrm{~m}$ dan $10 \mathrm{~m}$ (selisih $15 \mathrm{~m}$ ) berbeda sangat nyata dengan signifikansi kurang dari $1 \%$ (yaitu $0,0 \%$ ).

Perbedaan reduksi tingkat kebisingan oleh panjang klaster tanaman $25 \mathrm{~m}$ dan $7,5 \mathrm{~m}$ (selisih 17,5m) berbeda sangat nyata dengan signifikansi kurang dari $1 \%$ (yaitu $0,0 \%$ ). Perbedaan reduksi tingkat kebisingan oleh panjang klaster tanaman $20 \mathrm{~m}$ dan 7,5m (selisih 12,5m) berbeda sangat nyata dengan signifikansi kurang dari $1 \%$ (yaitu $0,3 \%$ ).

\section{KESIMPULAN}

Dari uraian di atas dapat disimpulkan bahwa semakin besar perbedaan panjang klaster tanaman untuk mereduksi tingkat kebisingan berpengaruh sangat nyata terhadap reduksi tingkat kebisingan.

\section{Ucapan Terima Kasih (jika diperlukan)}

Penulis mengucapkan terima kasih kepada Direktorat Riset dan Pengabdian Masyarakat Direktorat Jenderal Riset dan Pengembangan Kemenristekdikti yang telah mendanai kegiatan penelitian ini untuk tahun anggaran pendanaan penelitian tahun 2019 .

\section{DAFTAR PUSTAKA}

Badan Pusat Statistik. (2019). Jumlah Kendaraan Bermotor menurut Kabupaten/Kota dan Jenis Kendaraan di Provinsi Sumatera Selatan 2015, 2016 dan 2017. Palembang. Sumatera Selatan. https://sumsel.bps.go.id/dynamictab le/2016/11/07/259/jumlahkendaraan-bermotor-menurutkabupaten-kota-dan-jeniskendaraan-di-provinsi-sumateraselatan-2015-2017.html

Fang, C. F., \& Ling, D. L. (2003). Investigation of the Noise Reduction Provided by Tree Belts. Landscape and Urban Planning, 63, $187-195$.

Heryanto, S. (2004). Pengendalian Kebisingan pada Lingkungan Perkotaan. Jurnal Ilmiah Arsitektur Universitas Pelita Harapan, 1(2), $125-136$. 
Hidayat, I. W. (2010). Kajian Fungsi Ekologi Jalur Hijau Jalan sebagai Penyangga Lingkungan pada Tol Jagorawi. Jurnal Manusia dan Lingkungan, 17(2), $124-133$.

Keputusan Menteri Lingkungan Hidup Nomor 48. (1996). Baku Mutu Kebisingan.

Kusminingrum, N. (2008). Potensi Tanaman dalam Menyerap CO2 dan CO untuk mengurangi Dampak Pemanasan Global. Jurnal Pemukiman, 3(2), 96 - 128.

Nilson, M. E., Bengtsson, J., \& Klaeboe, R. (2015). Transport Noise Reduction: Environmental Methods for Transport Noise Reduction. Taylor and Francis Group. CRC. Press.

Price, M. A. (1988). Sound Attenuation Through Trees: Measurenment and Models. Journal of Accoustical Society of Americal, 84(5), 1836 1844.

Putri, Febriani, N., Ginting, D., \& Fitri, Y. (2016). Analisis Pengaruh Jumlah Kendaraan Bermotor terhadap Tingkat Kebisingan di Jalan Utama Kota Pekanbaru. In Prosiding $1^{\text {th }}$ Celscitech-UMRI 2016 (Vol. 1-September 2016, pp. SCI69 - SCI 72)

Rahmatunnisa, F. G., Sudarwati, M. R., \& Sufanir, A. M. S. (2017). Pengaruh Volume dan Kecepatan Kendaraan terhadap Tingkat Kebisingan pada Jalan DR. Djunjunan di Kota Bandung. In Industrial Research Workshop and National Seminar Politeknik Negeri Bandung 26-27 Juli 2017 (pp. 42 $-51)$.
Samara, Th., \& Tsitsoni, Th. (2007). Road Traffic Noise Reduction by Vegetation in the Ring Road of a Big City. In Proceeding of the International Conference on Environmental Management, Engineering, Planning and Economics 24 - 26 June 2007 (pp. 2591 - 2596).

Umiati, S. (2012). Pengaruh Pagar Tembok terhadap Tingkat Kebisingan pada Perumahan Jalan Ratulangi Makasar. Jurnal Rekayasa Sipil, 8(1), $21-28$. 